\title{
Use of Natalizumab in Patients with Multiple Sclerosis: 2015 Update
}

\author{
Paul W. O'Connor, Marcelo Kremenchutzky
}

Keywords: Clinical neurosciences, Multiple sclerosis

doi:10.1017/cjn.2015.296

Can J Neurol Sci. 2015; 42: 372-380

Natalizumab is a monoclonal antibody indicated in Canada as monotherapy for the treatment of multiple sclerosis (MS) patients with relapsing-remitting disease. Although natalizumab has been available in Canada since 2006, there remain elements of uncertainty among community and academic neurologists on how best to use this drug in clinical practice.

The following recommendations relating to the use of natalizumab in patients with MS represent a combined update of two previous communications by Canadian expert panels published in 2010 and 2012. ${ }^{1,2}$ The first of these was a clear and practical set of recommendations on the use of natalizumab in MS, based on available evidence and the panel's experience up to that time. ${ }^{1}$ The second was a more in-depth discussion of John Cunningham virus (JCV) testing for risk stratification for progressive multifocal leukoencephalopathy (PML). ${ }^{2}$ In the years since these two communications were published, there have been meaningful additions to the body of research on natalizumab in MS as well as a more substantial accumulation of real-world experience. The purpose of this article is to revise and add to the previous publications to reflect the latest available knowledge on the use of natalizumab, including long-term efficacy and real-world safety data with natalizumab in MS, appropriate monitoring strategies for treated patients, the use of the anti-JCV antibody index in risk stratification for natalizumabassociated PML, and management of PML and immune reconstitution inflammatory syndrome (IRIS). This update was developed by a national, independent expert panel that convened in September 2014.

\section{Update on EFFicaCy ANd SAFETy EVIDENCE WITH NATALIZUMAB IN MS}

The goal of treatment with natalizumab is "no evidence of disease activity," which is defined as no relapses, no new T2 or gadolinium-enhancing $(\mathrm{Gd}+)$ lesions on magnetic resonance imaging (MRI), and no disease progression as measured by the Expanded Disability Status Scale (EDSS). The short-term goal of therapy with natalizumab is to control disease activity-relapses, disability progression, and MRI metrics of MS. The long-term goal of therapy is to potentially prevent the development of progressive disease with its attendant disability, while preserving patient safety.
The Multinational Phase 3, Randomized, Double-Blind, Placebo-Controlled Efficacy and Safety Study of Oral MDV3100 in Patients With Progressive Castration-Resistant Prostate Cancer Previously Treated With Docetaxel-Based Chemotherapy (AFFIRM) phase III clinical trial of natalizumab monotherapy showed reductions in clinical and MRI parameters in patients with relapsing-remitting MS, with a statistically significant reduction in annualized relapse rate (ARR; 68\% at 1 year), which led to decreases in sustained progression of EDSS (42-54\% at 2 years), and the number of new or enlarging T2 lesions (83\%; all $\mathrm{p}<0.001$ compared with placebo) and $\mathrm{Gd}+$ lesions $(92 \% ; \mathrm{p}<0.001){ }^{3}$

In addition to AFFIRM and other clinical trials, which have the recognized limitations of short duration (i.e. 2 years relative to the lifelong disease), ${ }^{4,5}$ longer-term extension studies, and accumulated clinical experience support natalizumab's efficacy and tolerability profile.

The most recently published long-term data for natalizumab was from the Tysabri Observational Program, a prospective, observational, 10-year study (not a randomized controlled trial). ${ }^{6}$ In the 5-year interim analysis of 4821 patients (mean follow-up 26 months), $91 \%$ of whom received $\geq 1$ disease-modifying therapy (DMT) before initiating natalizumab therapy, mean ARR decreased from 1.99 in the 12 months before baseline to 0.31 on natalizumab therapy ( $84 \%$ reduction with $\mathrm{p}<0.0001$ ), and remained low. Additionally, mean EDSS scores remained unchanged up to 5 years in the analysis.

Other recent nonrandomized controlled trial evidence has shown that switching to natalizumab after failure of an injectable DMT (i.e. interferon beta [IFN- $\beta$ ], glatiramer acetate [GA]) is associated with significantly better disease control (fewer relapses, less disease progression as measured by EDSS, and fewer new MRI lesions) compared with switching to another injectable DMT. ${ }^{7,8}$ Furthermore, a propensity-matched analysis of the MSBase registry showed that patients who switched to natalizumab after failure of IFN- $\beta$ or GA had lower relapse rates than those who switched to fingolimod (ARR decreased from 1.5 to 0.2 with natalizumab, from 1.3 to 0.4 with fingolimod; $50 \%$ relative postswitch difference in relapse hazard $[p=0.002]) .{ }^{9}$ In a recently published analysis, treatment with natalizumab has also been shown to be associated with significantly faster recovery from a relapse compared with placebo $(55 \%$ and $67 \%$ increased probability of 12 -week confirmed recovery in patients with an increase in EDSS of $\geq 0.5$ or $\geq 1.0$ during relapse, respectively). ${ }^{10}$

\footnotetext{
From the Multiple Sclerosis Clinic, St. Michael's Hospital, University of Toronto, Toronto, Ontario, Canada (PWO'C); London Health Sciences Centre, Western University, London, Ontario, Canada (MK).

Received February 12, 2015. Final Revisions Submitted February 16, 2015.

Correspondence to: Marcelo Kremenchutzky, London Health Sciences Centre, 339 Windermere Road, London, Ontario, N6A 5A5, Canada. E-mail: mkremen2@uwo.ca.
} 
Balanced with the body of evidence to support natalizumab's efficacy, the safety profile of this compound is well-understood and is based on clinical experience with more than 132,600 patients who have been exposed to natalizumab to date (as of September 30, 2014). The most significant adverse event for these patients is the risk of PML. ${ }^{3,11-13}$ In this light, it is paramount that clinicians continuously perform a benefit-risk analysis in patients being considered for natalizumab therapy, taking into consideration the risk of disease activity along with the risk of a serious adverse event.

\section{Patient Selection}

The standard use of natalizumab is in patients with relapsingremitting MS with failure or insufficient response to an adequate course (i.e. at least 6 months) of one or more conventional DMTs, such as beta-interferons, GA, or oral agents. Failure or suboptimal response was defined by this expert panel as continued relapses or increased relapse rate from pretreatment levels and/or sustained worsening of neurological disability, with or without new lesions on MRI. With respect to the MRI criteria, the reference scan should be performed at least 6 months after treatment initiation, and the presence of $\mathrm{Gd}+$ lesions or three or more new $\mathrm{T} 2$ lesions observed on this or any subsequent scan should prompt a reevaluation of therapy. ${ }^{14}$ The degree to which relapse rate and disability progression are unacceptable is a judgment call to be made on a case-by-case basis by the treating neurologist. ${ }^{15}$

Importantly, use of natalizumab should occur when there is evidence of disease activity despite the use of a first-line agent. In general, patients with a lower EDSS score at the beginning of therapy are more likely to benefit from natalizumab.

Other patient groups that could be considered for natalizumab treatment include:

- Those with intolerability to first-line DMTs and evidence of inflammatory disease activity;

- Patients with rapidly evolving severe MS (two or more relapses with incomplete recovery within 1 year or two or more moderate to severe relapses with complete recovery within 1 year and an active MRI scan $[\geq 1 \mathrm{Gd}+$ enhancing lesion or three or more new T2 lesions]), regardless of prior exposure to treatment;

- Patients younger than 18 years of age who meet these criteria for treatment with natalizumab.

For older patients ( $>64$ years), there are insufficient data for the use of natalizumab; treatment should be considered with added caution because PML risk increases after age in the sixth decade. $^{16}$

There is currently no evidence to suggest that natalizumab would be effective in patients with worsening disease progression resulting from the presence of primary or secondary progressive MS (SPMS) disease alone; however, an ongoing trial of natalizumab in SPMS-A Clinical Study of the Efficacy of Natalizumab on Reducing Disability Progression in Subjects With SPMS ${ }^{17}$-will provide important information in this regard.

\section{Pretreatment Tests And Procedures}

The following recommendations outline what constitutes an appropriate workup before initiating treatment with natalizumab.
Immune competence should be assessed at baseline by the following tests; if any results are positive or abnormal, natalizumab should not be initiated until the cause of the immunocompromised status is known and has resolved:

- Clinical history, focusing on unusual or severe prior infections, any current infections, and prior exposure to chemotherapy (natalizumab is generally not recommended for patients with prior exposure to immunosuppressive therapy; however, they should be assessed on a case-by-case basis);

- Complete blood count and differential, focusing on lymphocyte count;

- HIV screening should be considered-natalizumab is not recommended by this panel for use in HIV-positive individuals.

Other recommended baseline tests to be conducted before initiation of natalizumab:

- Detailed medical history with full neurological examination and EDSS performed by a trained neurologist;

- General physical examination;

- Brain MRI at baseline, unless one is available from the previous 6 months (using a standardized MRI protocol; e.g. the Consortium of MS Centers protocol ${ }^{18}$ - a new protocol in development at the time of writing);

- Liver function tests;

- Pregnancy test;

- JCV antibody status - see the subsequent section for more detailed information on the JCV index and its ramifications.

\section{Other Considerations}

Tuberculosis testing should be considered where indicated (e.g. patients coming from areas where tuberculosis is endemic). A chest X-ray is not sensitive enough to identify latent tuberculosis; therefore, a tuberculin skin test can be useful in this setting. ${ }^{19}$ Patients with risk factors for malignancy should be evaluated on an individual basis. A cerebrospinal fluid examination is optional, and there is no specific need to do this. There is no evidence to suggest that varicella poses a special risk with this drug. Although no specific vaccinations are recommended before starting natalizumab, live or live-attenuated vaccines should be administered before initiating therapy.

\section{Recommendations For PML Risk Stratification INCORPORATING THE JCV INDEX}

Extensive research has been conducted to profile the risk of PML in patients treated with natalizumab. As a result, three risk factors have been identified: the presence of JCV antibodies, prior immunosuppression, and duration of therapy. Risk stratification for PML has been greatly refined since the introduction of the anti-JCV antibody index, an optical density measurement of antibody level. The overall JCV-positivity rates with this assay have ranged from approximately $50 \%$ to $60 \% .^{20-23}$

Since this index was introduced, we no longer simply consider a patient's JCV serostatus, but also take into account the magnitude of positivity. Subjects with higher anti-JCV antibody indices are at higher risk of PML than JCV-positive patients with lower indices. The results of a quantitative analysis of risk by anti-JCV antibody index are shown in Table $1 .{ }^{24}$ Note that there is a false-negative rate of approximately $2.0 \%$ to $2.5 \%$ per year, 
Table 1: PML risk estimates by index threshold in anti-JCV antibody-positive patients with no prior immunosuppressant use

\begin{tabular}{l|c|c|c}
\hline & \multicolumn{2}{|c}{ PML risk estimates per 1000 anti-JCV antibody-positive patients by natalizumab treatment duration (no prior IS use) } \\
\hline Anti-JCV Antibody Index & $\mathbf{1 - 2 4}$ months (99\% CI) & $\mathbf{2 5 - 4 8 ~ m o n t h s ~ ( 9 9 \% ~ C I ) ~}$ & 49-72 months (99\% CI) \\
\hline$\leq 0.9$ & $0.1(0-0.15)$ & $0.3(0-1.28)$ & $0.4(0-1.25)$ \\
\hline$\leq 1.1$ & $0.1(0-0.23)$ & $0.7(0-1.85)$ & $0.7(0-1.98)$ \\
\hline$\leq 1.3$ & $0.1(0-0.28)$ & $1.0(0-2.38)$ & $1.2(0-2.56)$ \\
\hline$\leq 1.5$ & $0.1(0-0.30)$ & $1.2(0.20-2.61)$ & $1.3(0.24-2.78)$ \\
\hline$>1.5$ & $1.0(0.84-1.07)$ & $8.1(7.06-8.98)$ & $8.5(7.41-9.46)$ \\
\hline No index* & $0.6(0.42-0.88)$ & $5.2(4.28-6.19)$ & $5.4(4.03-7.14)$ \\
\hline
\end{tabular}

PML risk estimates across anti-JCV antibody index thresholds were calculated based on the PML risk stratification algorithm (from September 2012) and predicted probabilities shown in Table 1 for the anti-JCV antibody-positive population at or below respective index thresholds from 0.9 to 1.5 . For index thresholds at or below 0.7, PML patient numbers were insufficient to allow for calculation of risk estimates.

*Based on existing PML risk stratification algorithm using September 2012 data for the anti-JCV antibody-positive group with no prior

immunosuppressant use.

CI: confidence interval; IS: immunosuppressant.

Reproduced from Plavina T, et al. Ann Neurol. 2014;76:802-12. Epub 2014 Oct 24. DOI: 10.1002/ana.24286. John Wiley \& Sons, Inc. Copyright @ 2014 Biogen Idec.

and seroconversion occurs in approximately $2 \%$ to $8 \%$ of natalizumab-treated patients per year. ${ }^{20,21}$ It is also important to note that there can be fluctuation in the JCV index at lower levels.

Table 2 shows the panel's recommendations for natalizumab therapy depending on these three risk factors. It should be stressed that the JCV index has no prognostic value among patients who have received prior immunosuppressant or chemotherapy.

Measurement of L-selectin levels may, in the future, be useful in terms of stratifying PML risk. Recent studies assessed lymphocyte surface expression of CD62L, also known as L-selectin, as a possible biomarker of PML risk in relapsingremitting MS patients treated with natalizumab. Schwab and colleagues acknowledged the difficulty of quantifying L-selectin/ CD62L expression and the need for additional validation of their hypothesis. ${ }^{25}$ As such, the clinical utility of this proposed biomarker in natalizumab-treated patients remains to be established, and further investigation is warranted.

\section{Recommendations on Washout Periods When Switching To Natalizumab}

With little evidence available on desirable washout periods, the decision on the appropriate duration when switching to natalizumab should be individualized.

A treatment-free period may not be desirable in all patients, particularly those with rapidly worsening disease and/or high disease activity. For the DMTs IFN- $\beta$ or GA, no washout is necessary. Similarly, for the oral DMTs dimethyl fumarate, fingolimod, and teriflunomide, no washout is typically necessary, unless there is significant lymphopenia (absolute lymphocyte count $<0.5 \times 1000 / \mathrm{mm}^{3}$ ). Treatment should not begin until the absolute lymphocyte count is $0.5 \times 1000 / \mathrm{mm}^{3}$ or higher.

The safety of treating patients previously exposed to chemotherapeutic agents remains a highly controversial topic. The use of natalizumab following chemotherapy should only be considered with extreme caution and only in expert hands because of the increased risk of PML.

\section{Recommendations for Monitoring DURing Natalizumab TreatMenT}

Patients should be evaluated at a minimum of every 6 months, and more frequently if there are any concerns such as hypersensitivity reactions, infusion reactions, new neurological symptoms, or disease worsening.

The following evaluations should form part of routine followup visits:

- History of any new neurological symptoms and complete neurological examination.

- Updated medical history with a physical examination looking particularly for signs of opportunistic infection, malignancy (skin or otherwise), and liver disease.

- Liver function tests in patients at risk for hepatotoxicity. Some cases of hepatotoxicity have been reported in patients with preexisting liver disease or in the presence of other drugs that have been associated with hepatic injury. In some patients, liver injury recurred upon rechallenge.

- Neutralizing antibodies (NAbs) testing at 6 months after initiation of natalizumab therapy, or earlier in a patient who has experienced an unusual drug reaction, such as hives. The drug manufacturer arranges for reimbursed, third-party NAbs testing.

- Anti-JCV index, at least every 6 months, and potentially more frequently (e.g. 3 months) for those with higher risk of PML.

- Active evaluation of patients (clinically and radiologically) for any indicators of PML (see the following section) or disease worsening. The recommended MRI sequences include two- or three-dimensional axial fluid attenuation inversion recovery (FLAIR) and axial diffusion-weighted imaging ${ }^{26}$; a contrast agent is not required. ${ }^{27}$

When patients are initiated on natalizumab, enrolment in longterm safety/observational registries is recommended, if available, to help provide further information on long-term efficacy and safety. 
Table 2: Summary of recommendations for natalizumab use by presence of absence of the three major risk factors

\begin{tabular}{|c|c|c|c|c|c|}
\hline $\begin{array}{l}\text { Anti-JCV antibody index/ } \\
\text { serostatus }\end{array}$ & $\begin{array}{l}\text { Low index or } \\
\text { negative }\end{array}$ & High index & High index & Positive* & Positive* \\
\hline Prior immunosuppressant use & Yes or no & No & No & Yes & Yes \\
\hline $\begin{array}{l}\text { Duration of natalizumab } \\
\text { treatment }\end{array}$ & $0-2$ years & $0-2$ years & $>2$ years & $0-2$ years & $>2$ years \\
\hline Estimated risk of PML $(95 \% \mathrm{CI})$ & $\leq 0.10 / 1000(0-0.56)$ & $0.53 / 1000(0.33-0.81)$ & $3.9 / 1000(3.0-4.9)$ & $1.5 / 1000(0.83-2.5)$ & $10.6 / 1000(7.7-14.2)$ \\
\hline Initiation of natalizumab & $\begin{array}{l}\text { An appropriate choice } \\
\text { when switching from } \\
\text { conventional DMT. }\end{array}$ & $\begin{array}{l}\text { Index result does not } \\
\text { change strategy during } \\
\text { first } 2 \text { years because } \\
\text { PML risk is low. } \\
\text { Inform patient of index } \\
\text { result. }\end{array}$ & N/A & $\begin{array}{l}\text { Discuss risk of PML } \\
\text { with patient. } \\
\text { These patients often } \\
\text { have aggressive } \\
\text { disease. } \\
\text { Need for effective } \\
\text { treatment may } \\
\text { outweigh risk. }\end{array}$ & N/A \\
\hline $\begin{array}{l}\text { Maintenance of natalizumab } \\
\text { treatment }\end{array}$ & $\begin{array}{l}\text { Continue as long as } \\
\text { effective and low index } \\
\text { (spares drug holidays). } \\
\text { PML risk remains very } \\
\text { low with every low } \\
\text { index or negative test. }\end{array}$ & $\begin{array}{l}\text { Maintain (if effective) } \\
\text { until } 2 \text { years then } \\
\text { reassess benefits and } \\
\text { risks. }\end{array}$ & $\begin{array}{c}\text { Discuss risk with } \\
\text { patient. } \\
\text { Probably continue } \\
\text { natalizumab if } \\
\text { aggressive disease; less } \\
\text { compelling in mild-to- } \\
\text { moderate disease. }\end{array}$ & $\begin{array}{l}\text { Maintain (if effective) } \\
\text { until } 2 \text { years then } \\
\text { reassess benefits and } \\
\text { risks. }\end{array}$ & $\begin{array}{c}\text { Discuss risk of } \\
\text { continued therapy and } \\
\text { other potential } \\
\text { treatment options. }\end{array}$ \\
\hline Monitoring and management & $\begin{array}{l}\text { Routine clinical and } \\
\text { MRI examination (at } \\
\text { least every } 12 \text { months). }\end{array}$ & $\begin{array}{l}\text { Routine clinical and } \\
\text { MRI examination (at } \\
\text { least every } 6 \text { months). }\end{array}$ & $\begin{array}{l}\text { Increased clinical } \\
\text { vigilance: examination } \\
\text { at least every } 6 \text { months. } \\
\text { MRI every 4-6 months. }\end{array}$ & $\begin{array}{l}\text { Increased clinical } \\
\text { vigilance: examination } \\
\text { at least every } 6 \text { months. } \\
\text { MRI every 4-6 months. }\end{array}$ & $\begin{array}{l}\text { Heightened clinical } \\
\text { vigilance: examination } \\
\text { at least every } 6 \text { months. } \\
\text { MRI every 4-6 months. }\end{array}$ \\
\hline Retest for anti-JCV antibodies? & $\begin{array}{l}\text { Repeat anti-JCV } \\
\text { antibody index every } \\
\text { six months }\end{array}$ & Yes & Yes & Yes & Yes \\
\hline
\end{tabular}

*Anti-JCV antibody index has no prognostic utility in patients with prior immunosuppressant use.

CI: confidence interval.

Adapted from O’Connor PW. Can J Neurol Sci. 2012;39:670-5.

\section{RECOMMENDATIONS FOR IDENTIFICATION AND MANAGEMENT OF Possible PML Cases}

Patient and, where applicable, caregiver education is a critical component of vigilance for PML. Before initiating therapy with natalizumab, patients should be informed of the risks of PML and be provided with information about the drug, its potential side effects, how to recognize signs and symptoms of PML, and what to do if new neurological symptoms develop.

\section{Identification of Possible PML Cases}

All patients should be instructed to promptly report any new neurological symptoms to their clinician, and reminders should be given to patients at each clinical visit. Tables 3 and 4 outline clinical and MRI features that help to distinguish PML from MS relapses. $^{28,29}$

An algorithm for evaluating possible PML cases has been proposed by the International Multiple Sclerosis Expert Forum and adapted by this panel (Figure 1). ${ }^{30}$ If there is suspicion of PML, dosing should be suspended, an MRI with Gd enhancement and diffusion-weighted imaging should be obtained as soon as possible, and the drug manufacturer should be contacted. If the MRI shows features suggestive of PML, a cerebrospinal fluid sample should be obtained and tested using polymerase chain reaction for the presence of JCV DNA, the causative agent of PML. Natalizumab redosing should only be initiated if the diagnosis of PML is excluded and the continuation of treatment is deemed by the clinician to be appropriate in an individual patient.

\section{Management of a Confirmed PML Case}

The development of PML can be fatal; however, if cases are identified and treated at an early stage, the prognosis may be more favourable. ${ }^{31}$ At this time, it is recommended that dosing be suspended in patients with confirmed PML and that immunoadsorption or plasma exchange therapy be instituted to rapidly remove natalizumab from plasma and to restore normal leukocyte function. ${ }^{32,33}$ This process involves a recommended five exchanges within 2 weeks of natalizumab cessation.

MS patients who develop PML are at risk of developing IRIS within 1 to 3 months of natalizumab discontinuation. Immunoadsorption and plasma exchange may increase the probability and hasten the onset of IRIS. Although IRIS could be considered a desirable outcome insofar as it heralds the recovery of the immune system, it can potentially be fatal. There are no large-scale studies defining best practice in management of IRIS; however, cautious use of steroids may be helpful. Prophylactic steroid use in the absence of IRIS should be avoided. ${ }^{34}$ In addition, a report of an individual case of IRIS successfully treated with off-label maraviroc suggests that this agent may be beneficial for some patients with IRIS. $^{35}$ 
Table 3: Clinical signs and symptoms of typical MS relapses and PML

\begin{tabular}{l|l|l}
\hline & MS & PML \\
\hline Onset & Acute & Subacute \\
\hline Evolution & $\bullet$ Over hours to days & Over weeks \\
& $\bullet$ Pormally stabilize & \\
\hline Clinical presentation & $\bullet$ Resolve spontaneously or with treatment \\
& $\bullet$ Diplopia & $\bullet$ Cortical symptoms/signs \\
& $\bullet$ Opehavioural and neuropsychological alteration \\
& $\bullet$ Myelopathy & $\bullet$ Hetrochiasmal visual deficits \\
& $\bullet$ Ataxia & \\
\hline
\end{tabular}

Adapted from Kappos L, et al. Lancet Neurol. 2007;6:431-41.

Table 4: Recommendations for the diagnosis of early PML in natalizumab-treated multiple sclerosis patients

\begin{tabular}{|c|c|}
\hline Features & Characteristics \\
\hline Location & Subcortical location is the prime site, thereby involving U-fibres; cortex and basal ganglia are often involved; often bilateral* \\
\hline Size & Usually $>3 \mathrm{~cm}$ \\
\hline Borders & Sharp toward the grey matter, ill-defined toward the white matter \\
\hline Mode of extension & Lesions increase in size and new lesions appear \\
\hline Mass effect & No mass effect in small or large lesions \\
\hline T2W images & Always hyperintense \\
\hline T1W images & Typically hypointense; no reversion of signal intensity; hyperintensity is suggestive of PML-IRIS* \\
\hline FLAIR & Always hyperintense; better appreciated than on $\mathrm{T} 2 \mathrm{~W}$ images \\
\hline DWIs & Always hyperintense; in larger lesion there is a hyperintense rim at the lesion's edge* \\
\hline Perilesional & Small, punctate T2-hyperintense lesions in the immediate vicinity of the main lesion are often present* \\
\hline Enhancement & Frequent enhancement, punctate and/or rimlike \\
\hline Atrophy & No atrophy in the early phase \\
\hline
\end{tabular}

*Features especially helpful in the identification of small PML lesions. T1W, T1-weighted; T2W, T2-weighted.

Reproduced from Yousry TA, et al. Ann Neurol. 2012;72(5):779-87. DOI: 10.1002/ana.23676. John Wiley \& Sons, Inc. Copyright @ 2012 American

Neurological Association.

The treatment of MS in PML survivors post natalizumab is controversial. The use of natalizumab is not recommended, but no further data exist to direct MS treatment.

\section{Other OpPortunistic Infections ANd MaLignancies}

There have been no statistically significant differences in incidence rates of opportunistic infections and malignancies in patients treated with natalizumab compared with placebo in randomized trials. ${ }^{3,36}$ The incidence of infections and malignancies in the postmarketing setting is being actively monitored in long-term registry trials of natalizumab therapy. To date, there have been no unexpected serious adverse events, and the incidence of serious adverse events (including infections and hypersensitivity reactions) has been similar to that observed in clinical trials. ${ }^{37}$

Malignancy has been a theoretical concern with monoclonal antibody therapies. Although there were no observed differences in incidence rates or the nature of malignancies between natalizumab- and placebo-treated patients in clinical trials, ${ }^{3,34}$ clinicians should be vigilant in monitoring patients for signs and symptoms of malignancy.

\section{Recommendations for Managing Potential Adverse EVENTS}

In general, natalizumab has been associated with a favourable tolerability profile, with few treatment-emergent adverse events. ${ }^{3}$ See Table 5 for a summary of selected adverse events and recommended management.

Serious adverse events should be reported to Health Canada's Vigilance Program at the National Adverse Event Reporting Centre (toll-free at 866-234-2345 or by e-mail to Canada Vigilance@hc-sc.gc.ca). The reporting of PML is mandatory.

\section{Possible Considerations For Withholding Natalizumab THERAPY}

\section{Infection}

Based on the theoretical risks associated with an immunocompromised status, natalizumab administration should be 


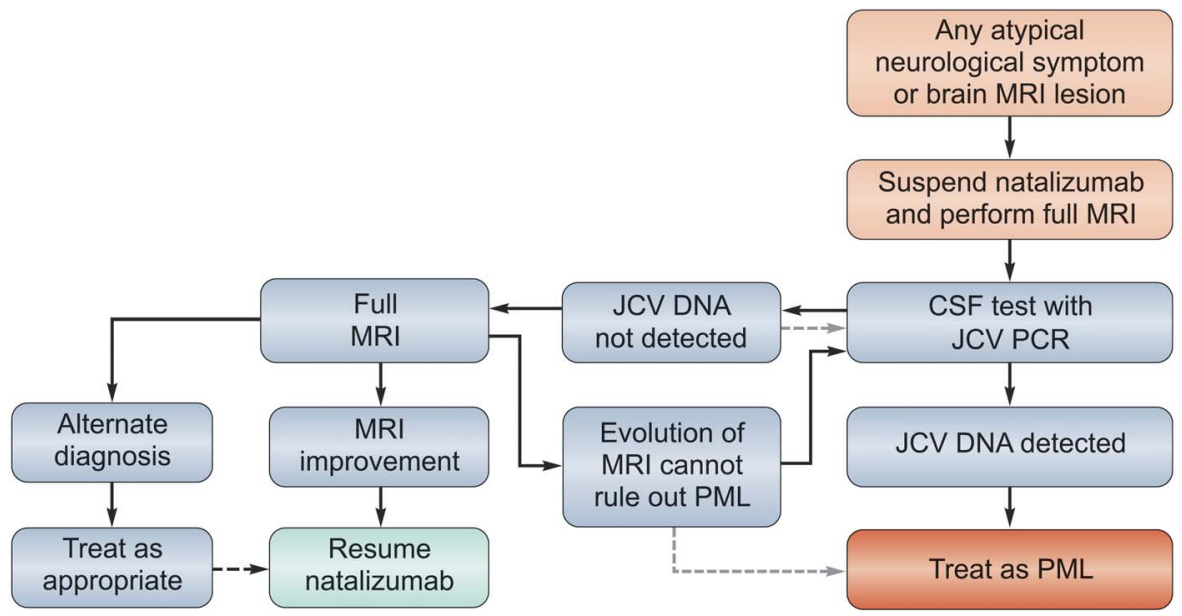

Figure 1: Suggested algorithm for natalizumab-treated MS patients with atypical MRI lesion or neurological symptoms

Full MRI = FLAIR, T2 proton density, DWI, T1 +Gd. Detection of JCV DNA should be based on ultrasensitive quantitative PCR procedure. In case of multiple negative JCV PCR results, NAbs testing and alternative diagnosis should be considered. Disease activity recurrence may interfere with the algorithm beyond 6 to 8 weeks after treatment interruption. Atypical neurological symptom or lesion as defined by any of the following aspects: peripheral cortical, juxta- or cortical location; basal ganglia location; cluster of punctate nodules; enlarging lesion(s) on repeat scans.

CSF, cerebrospinal fluid; PCR, polymerase chain reaction; PML, progressive multifocal leukoencephalopathy.

Adapted from The International Multiple Sclerosis Expert Forum (IMSEF) Group. Manuscript In preparation.

withheld in patients with active, acute infections until the infection resolves. In the case of a viral cold or influenza, infusions can be administered in the absence of fever. For patients with febrile cold or flu infections, infusions should be withheld until the fever resolves. Likewise, patients should not be infused with natalizumab until an episode of shingles has resolved.

\section{PML}

Natalizumab dosing should be suspended in patients with new neurological symptoms suggestive of PML (see earlier section on identification and management of possible PML cases).

\section{Pregnancy and Lactation}

Reports from an ongoing pregnancy registry suggest that teratogenicity has not occurred when female patients receiving natalizumab have become pregnant. ${ }^{38}$ Although there are no evidence-based data available to guide clinical practice on this issue, it is advised that patients planning a pregnancy discontinue natalizumab 2 to 3 months before conceiving; a break in therapy may be associated with disease worsening. Information on MS patients who continued natalizumab during the third trimester of pregnancy indicates that reversible hematologic adverse events such as thrombocytopenia and anemia can occur in the infant. Natalizumab was detectible in umbilical cord blood. A mother's benefit-risk profile should be reassessed shortly after delivery. If she is at significant risk of relapse, by virtue of having had severe pretreatment disease, she should be advised to restart natalizumab therapy immediately post-partum. ${ }^{39}$
Women should not breastfeed their infants while receiving natalizumab because it is not known whether this agent crosses into breast milk.

\section{Vaccinations WhiLe On Treatment}

There are no data available on the effects of vaccination in patients receiving natalizumab, nor are there data to suggest that infections can be transmitted via live or live-attenuated vaccines administered to patients receiving natalizumab. However, this group does not recommend the use of live or live-attenuated vaccines for patients receiving natalizumab; these vaccines should be administered before initiation of natalizumab therapy, wherever possible.

Evidence is conflicting regarding the effectiveness of killed vaccines in patients receiving natalizumab.

\section{Recommended Duration of Natalizumab Therapy}

The optimal duration of natalizumab therapy has yet to be elucidated and remains a controversial issue. See Table 2 for recommendations for duration of therapy based on presence or absence of major risk factors for PML.

Recent reports on long-term natalizumab therapy from prospective, observational studies suggest that the incidence and type of adverse events seen with long-term treatment are consistent with those seen with short-term treatment. ${ }^{6,40}$ In the Natalizumab (Tysabri) Re-Initiation of Dosing (STRATA) redosing trial, 1094 patients who previously received natalizumab in a clinical trial (AFFIRM ${ }^{3}$ or Safety and Efficacy of Natalizumab in Combination with Interferon Beta-1a in Patients with 
Table 5: Management of adverse events during natalizumab therapy

\begin{tabular}{|c|c|c|}
\hline Adverse event & Remarks & Recommendation for management \\
\hline Headache & $\begin{array}{l}\text { One of the most common adverse events of natalizumab } \\
\text { therapy }\end{array}$ & Over-the-counter analgesics (e.g. acetaminophen, ibuprofen) \\
\hline Mild cutaneous rash/flushing & Rare, generally disappear spontaneously & $\begin{array}{l}\text { Consider preemptive antihistamine and/or cortisone before } \\
\text { natalizumab infusion }\end{array}$ \\
\hline Fatigue & $\begin{array}{l}\text { May occur in the days before and following the first few } \\
\text { natalizumab infusions }\end{array}$ & Generally self-limiting; no treatment required \\
\hline $\begin{array}{l}\text { Urticaria or other infusion-related } \\
\text { hypersensitivity reaction }\end{array}$ & Rare & Stop infusion and permanently discontinue natalizumab \\
\hline Herpes simplex infection & $\begin{array}{l}\text { History of herpes infection is not a reason to avoid natalizumab } \\
\text { use }\end{array}$ & Manage symptomatically, including use of valacyclovir \\
\hline
\end{tabular}

Relapsing Remitting Multiple Sclerosis; SENTINEL ${ }^{36}$ ) received an infusion of $300 \mathrm{mg}$ once every 4 weeks for up to 240 weeks. With the exception of PML risk, which increased with treatment duration (14 cases; $1.3 \%$ risk over the 240 -week period), serious adverse events in STRATA were consistent with natalizumab's known safety profile; evolution of EDSS scores and relapse rates were consistent with the known efficacy profile. ${ }^{39}$

At this time, this panel of experts does not endorse routine "drug holidays" (e.g. utilization of natalizumab as an intermittent therapy) in patients who are demonstrating beneficial effects of therapy.

\section{Possible Considerations For Discontinuation Of Therapy}

\section{Hypersensitivity}

The development of a bona fide hypersensitivity reaction (e.g. hives) is an indication to immediately and permanently discontinue natalizumab therapy.

Loss or lack of efficacy, defined as the failure of natalizumab to mitigate the pretreatment relapse pattern after a minimum of 1 year of therapy, constitutes grounds for considering discontinuation. Confirmed EDSS progression alone should not necessarily be sufficient justification for discontinuing therapy. Progressively worsening disease observed on two consecutive visits and/or worsening MRI activity can be considered indicators for loss or lack of efficacy and should be closely monitored.

\section{PML and JCV Index}

In the event that PML is identified, natalizumab must be stopped immediately. If the anti-JCV antibody levels in plasma/ serum rise above 3.0, as measured by JCV index, even in the absence of symptoms or signs of PML, consideration should be given to discontinuing natalizumab.

\section{Neutralizing Antibodies}

In the event that a positive result is obtained, the NAbs test should be repeated as soon as possible; natalizumab infusions should be suspended until the results of the second NAbs test are available. Natalizumab should be permanently discontinued in patients with persistently positive NAbs (at least two separate tests). Because NAbs generally do not develop after 6 months of therapy, there is no indication for routine periodic NAbs testing beyond this timeframe, unless indicated (e.g. development of hives or radiologic evidence of loss of response).
The drug manufacturer arranges for reimbursed third-party NAbs testing; protocols for sample acquisition and shipping can be obtained directly from the manufacturer.

\section{Return of Disease Activity}

Evidence suggests that natalizumab provides beneficial effects shortly after initiation of therapy, but that it does not induce long-lasting remissions after drug discontinuation. ${ }^{3}$ Therefore, continuous treatment is required for the maintenance of clinical benefits. The suspension of natalizumab in 2005, resulting from the occurrence of two cases of PML in MS patients during clinical trials, provides important information on patient outcomes following discontinuation of natalizumab therapy. In a minority of cases, rebound of disease activity can occur, defined as in excess of pretreatment, with relapse and numerous $\mathrm{Gd}+$ lesions. Such patients cannot be reliably identified. Patients in the AFFIRM study who discontinued natalizumab therapy had a return of clinical and MRI disease activity to on-study placebo levels within 4 months. $^{41}$

Clinicians should closely monitor for infusion reactions and NAbs in any patient who discontinues or interrupts treatment shortly after initiation of therapy and who experiences a return of disease activity. Patients who discontinue treatment after only two infusions and are then reinfused at a later time are more likely to develop infusion reactions and NAbs, ${ }^{42}$ and appear to be more susceptible to a rebound in T2 disease activity upon discontinuation after receiving only a few infusions. ${ }^{43}$

\section{Management of Patients After Natalizumab DisconTINUATION}

Treatment after natalizumab should be individualized and can either be an oral or traditional injectable DMT. Patients should start their next DMT as soon as possible to help prevent return of disease activity. ${ }^{44}$ This panel recommends that the maximum washout period be no more than 4 weeks before starting most other DMTs. In the case of alemtuzumab, the optimal washout period after stopping natalizumab is unclear and somewhat controversial. In the absence of evidence, the panel recommends that this decision be individualized for each patient, taking into account the reason for the switch in therapy, the specific patient's risk of relapse, and his or her risk of developing PML. The use of chemotherapy immediately after natalizumab should only be considered with extreme caution and only in expert hands. 
After natalizumab cessation, an MRI should be performed within 4 to 6 months to assess for return of disease activity, and to monitor for PML for up to 6 months after discontinuing natalizumab.

\section{Conclusions}

In the 5 years that have elapsed since our first article on this topic, we have expanded our knowledge on several topics related to the use of natalizumab, including:

- Long-term efficacy data with natalizumab in MS-low risk of relapse and high rates of disease stability (by EDSS and MRI);

- Real-world safety of natalizumab, thanks to widespread clinical use and the focus on pharmacovigilance;

- Appropriate monitoring of treated patients;

- The prognostic significance of the JCV index in risk stratification for natalizumab-associated PML; and

- Management of PML and IRIS.

Strong evidence supports the efficacy of natalizumab in patients with MS who have signs of high or ongoing disease activity despite first-line therapy (e.g. clinical relapses with or without new MRI lesions). Although this agent has a favourable tolerability profile, its associated risk of PML warrants careful patient selection, ongoing monitoring, and clinical vigilance after institution of therapy.

Clinical practice will continue to evolve and be guided by available evidence and growing practical experience with this agent. Risk stratification has improved, but remains to be optimized. At this time, it is recommended that patients treated with natalizumab be:

1. Carefully selected based on an individualized benefit-risk assessment.

2. Vigilantly monitored while on natalizumab therapy to proactively address any safety issues that may occur, particularly PML.

3. Routinely assessed for continued evidence of benefit of therapy with treatment discontinued in the absence of clinical and MRI benefits.

\section{DisClosures}

PWO'C has received honoraria from and served as a consultant to Biogen Idec. MK has served as a researcher and consultant and received research grants and consulting fees from Biogen, Genzyme, and Novartis; served as a researcher for and received research grants from Bayer, Sanofi, Teva, and Canadian Institutes of Health Research; and received operational grants from the MS Society of Canada.

\section{ACKNOWLEDGMENTS}

These expert panel recommendations were prepared by Drs. Paul O'Connor and Marcelo Kremenchutzky, with input from a forum of Canadian MS neurologists experienced with natalizumab therapy. Members of the expert panel are: K. Alikhani, V. Bhan, F. Emond, P. Giacomini, M. Girard, F. Grand'Maison, Y. Lapierre, F. Jacques, J. Oh, D. Selchen, and A. Traboulsee.
A steering committee of Canadian neurologists specialized in the treatment of multiple sclerosis convened to update previously published recommendations on the optimal management of patients on natalizumab. The steering committee was paid an honorarium for its participation at the meeting by Biogen Idec. These recommendations were prepared by Drs. Paul O'Connor and Marcelo Kremenchutzky, with input from committee members. Biogen Idec provided funding for medical writing support for manuscript development and reviewed the final version of the paper for medical accuracy, but did not direct editorial content. The authors had full editorial control of the manuscript and provided their final approval of all content.

\section{REFERENCES}

1. O'Connor PW. Use of natalizumab in multiple sclerosis patients. Can J Neurol Sci. 2010;37:98-104.

2. O'Connor PW. Natalizumab risk stratification: role of a two-step anti-JCV antibody assay. Can J Neurol Sci. 2012;39:670-5.

3. Polman $\mathrm{CH}$, O'Connor PW, Havrdova E, et al. A randomized placebo-controlled trial of natalizumab for relapsing multiple sclerosis. N Engl J Med. 2006;354:899-910.

4. Marrie RA. You get what you measure: evaluating endpoints in MS clinical trials. Neurology. 2008;71:620-1.

5. Koch-Henriksen N. No shortcuts to outcome in MS clinical trials? Neurology. 2009;72:686-7.

6. Butzkueven H, Kappos L, Pellegrini F, et al. Efficacy and safety of natalizumab in multiple sclerosis: interim observational programme results. J Neurol Neurosurg Psychiatry. 2014;85:1190-7.

7. Prosperini L, Giannì C, Leonardi L, et al. Escalation to natalizumab or switching among immunomodulators in relapsing multiple sclerosis. Mult Scler. 2012;18:64-71.

8. Trojano M, Spelman T, Kalincik T, et al. After a relapse, patients who switch to natalizumab have better outcomes than those who switch between platform therapies [EFNS/ENS Oral presentation OS4203]. EFNS Eur J Neurol. 2014;21(Suppl. 1):101.

9. Kalincik T, Horakova D, Spelman T, et al. Switch to natalizumab versus fingolimod in active relapsing-remitting multiple sclerosis. Ann Neurol. 2015;77(3):425-35.

10. Lublin FD, Cutter G, Giovannoni G, Pace A, Campbell NR, Belachew S. Natalizumab reduces relapse clinical severity and improves relapse recovery in MS. Mult Scler Relat Disord. 2014;3:705-11.

11. Langer-Gould A, Atlas SW, Green AJ, Bollen AW, Pelletier D. Progressive multifocal leukoencephalopathy in a patient treated with natalizumab. N Engl J Med. 2005;353:375-81.

12. Kleinschmidt-DeMasters BK, Tyler KL. Progressive multifocal leukoencephalopathy complicating treatment with natalizumab and interferon-beta-1a for multiple sclerosis. N Engl J Med. 2005;353:369-74.

13. Van Assche G, Van Ranst M, Sciot R, et al. Progressive multifocal leukoencephalopathy after natalizumab therapy for Crohn's disease. N Engl J Med. 2005;353:362-8.

14. Sormani MP, Rio J, Tintoré M, et al. Scoring treatment response in patients with relapsing multiple sclerosis. Mult Scler. 2013;19:605-12.

15. Freedman MS, Selchen D, Arnold DL, et al. Treatment optimization in MS: Canadian MS Working Group updated recommendations. Can J Neurol Sci. 2013;40:307-23.

16. Brew BJ, Davies NW, Cinque P, Clifford DB, Nath A. Progressive multifocal leukoencephalopathy and other forms of JC virus disease. Nat Rev Neurol. 2010;6:667.

17. Mikol D, Freedman MS, Goldman MD, et al. ASCEND study of natalizumab efficacy on reducing disability in patients with secondary progressive multiple sclerosis: baseline demographics and disease characteristics. Poster presented at: 29th Congress of the European Committee for Treatment and Research in Multiple Sclerosis; October 2-5, 2013; Copenhagen, Denmark. 
18. Consortium of MS Centers. Consortium of MS Centers MRI protocol for the diagnosis and follow-up of MS. Available at: http://c.ymcdn.com/sites/www.mscare.org/resource/collection/ 9C5F19B9-3489-48B0-A54B-623A1ECEE07B/mriprotocol2009.pdf

19. Mulero P, Belén Caminero A, José Neri Crespo M, Fernández-Herranz R, Téllez Lara N. Latent tuberculosis seems not to reactivate in multiple sclerosis patients on natnatalizumab. J Neuroimmunol. 2012;243:103-5.

20. Gorelik L, Lerner M, Bixler S, et al. Anti-JC virus antibodies: implications for PML risk stratification. Ann Neurol. 2010;68:295-303.

21. Bozic C, Richman S, Plavina T, et al. Anti-John Cunningham virus antibody prevalence in multiple sclerosis patients: baseline results of STRATIFy-1. Ann Neurol. 2011;70:742-50.

22. Moiola 1, Sangalli F, Martinelli V, et al. Prevalence of anti-JCV antibodies in a cohort of natalizumab-treated multiple sclerosis patients from Italy. Neurology. 2011;76(Suppl 4):S30.007-1.

23. Bhan V, Lapierre Y, Freedman MS, et al. Anti-JC virus antibody prevalence in Canadian MS patients. Can J Neurol Sci. 2014;41:748-52.

24. Plavina T, Subramanyam M, Bloomgren G, et al. Anti-JC virus antibody levels in serum or plasma further define risk of natalizumab-associated progressive multifocal leukoencephalopathy. Ann Neurol. 2014;76:802-12.

25. Schwab N, Schneider-Hohendorf T, Posevitz V, Breuer J, Göbel K, Windhagen $\mathrm{S}$, et al. L-selectin is a possible biomarker for individual PML risk in natalizumab-treated MS patients. Neurology. 2013;81:865-71.

26. Wattjes MP, Barkhof F. Diagnosis of natalizumab-associated progressive multifocal leukoencephalopathy using MRI. Curr Opion Neurol. 2014;27:260-70.

27. Richert N, Bloomgren G, Cadavid D, Dong-Si T, Richman S, Ticho B. Imaging findings for PML in natalizumab-treated MS patients. Mult Scler. 2012;18(Suppl. 4):27-8.

28. Kappos L, Bates D, Hartung HP, et al. Natalizumab treatment for multiple sclerosis: recommendations for patient selection and monitoring. Lancet Neurol. 2007;6:431-41.

29. Yousry TA, Pelletier D, Cadavid D, et al. Magnetic resonance imaging pattern in natalizumab-associated progressive multifocal leukoencephalopathy. Ann Neurol. 2012;72:779-87.

30. The International Multiple Sclerosis Expert Forum (IMSEF) Group. Natalizumab treatment guidelines. Manuscript in preparation.

31. Dong-Si T, Richman S, Wattjes MP, Wenten M, Gheuens S, Philip J, et al. Outcome and survival of asymptomatic PML in natalizumab-treated MS patients. Ann Clin Transl Neurol. 2014; 1:755-64

32. Khatri BO, Man S, Giovannoni G, et al. Effect of plasma exchange in accelerating natalizumab clearance and restoring leukocyte function. Neurology. 2009;72:402-9.
33. Dahlhaus S, Hoepner R, Chan A, et al. Disease course and outcome of 15 monocentrically treated natalizumab-associated progressive multifocal leukoencephalopathy patients. J Neurol Neurosurg Psychiatry. 2013;84:1068-74.

34. Antoniol C, Jilek S, Schluep M, et al. Impairment of JCV-specific T-cell response by corticotherapy: effect on PML-IRIS management? Neurology. 2012;79:2258-64.

35. Giacomini PS, Rozenberg A, Metz I, Araujo D, Arbour N, Bar-Or A. Maraviroc and JC virus-associated immune reconstitution inflammatory syndrome. N Engl J Med. 2014;370:486-8.

36. Rudick RA, Stuart WH, Calabresi PA, et al. Natalizumab plus interferon beta-1a for relapsing multiple sclerosis. N Engl J Med. 2006;354:911-23.

37. Panzara MA, Baldinetti F, Belcher G, et al. Natalizumab utilization and safety in patients with relapsing MS: Updated results from TOUCH ${ }^{\mathrm{TM}}$ and TYGRIS. Poster presented at: 24th Congress of the European Committee for Treatment and Research in Multiple Sclerosis (with ACTRIMS and LACTRIMS); September 17-20, 2008; Montreal, Canada.

38. Cristiano L, Friend S, Bozic C, et al. Evaluation of pregnancy outcomes from the TYSABRI ${ }^{\circledR}$ (natalizumab) Pregnancy Exposure Registry [AAN abstract]. Neurology. 2013;80(Meeting Abstracts 1):P02.127.

39. Haghikia A, Langer-Gould A, Rellensmann G, et al. Natalizumab use during the third trimester of pregnancy. JAMA Neurol. 2014;71:891-5.

40. O'Connor P, Goodman A, Kappos L, et al. Long-term safety and effectiveness of natalizumab redosing and treatment in the STRATA MS Study. Neurology. 2014;83:78-86.

41. O'Connor PW, Goodman A, Kappos L, et al. Results of clinical and magnetic resonance imaging analyses following cessation of natalizumab dosing in patients with multiple sclerosis. Poster presented at: 22nd Congress of the European Committee for Treatment and Research in Multiple Sclerosis; September 27-30, 2006; Madrid, Spain.

42. O'Connor P, Goodman A, Kappos L, et al. Safety of natalizumab upon re-dosing: preliminary results from STRATA study. Poster presented at: 23rd Congress of the European Committee for Treatment and Research in Multiple Sclerosis; October 11-14, 2007; Prague, Czech Republic.

43. Vellinga MM, Castelijns JA, Barkhof F, Uitdehaag BM, Polman CH. Postwithdrawal rebound increase in $\mathrm{T} 2$ lesional activity in natalizumab-treated MS patients. Neurology. 2008;70(13 Pt 2):1150-1.

44. Iaffaldano $\mathrm{P}$, Lepore $\mathrm{V}$, Lucisano $\mathrm{G}$, et al. Risk of relapse after natalizumab discontinuation: which is the best treatment option? Poster presented at: Joint Meeting of the European Committee for Treatment and Research in Multiple Sclerosis and the Americas Committee for Treatment and Research in Multiple Sclerosis; September 10-13, 2014; Boston, MA. 